\title{
Radiation spectrum of an electron moving in a spiral in medium
}

\author{
A.V.Konstantinovich*, I.A.Konstantinovich \\ Fedkovych Chernivtsi National University, 2, Kotsyubinsky Str., Chernivtsi, 58012, Ukraine
}

Received September 4, 2006, in final form December 27, 2006

\begin{abstract}
The action of the Doppler effect on the particularities of radiation power spectral distribution of an electron moving in a spiral in a medium has been investigated near the Cherenkov threshold. The fine structure of the electromagnetic radiation spectrum at the Cherenkov threshold and the synchrotron-Cherenkov radiation spectrum for an electron moving along a spiral with non-relativistic longitudinal component of the velocity (i.e., the component parallel to the magnetic induction vector) in a transparent isotropic medium have been obtained and studied.
\end{abstract}

Key words: synchrotron radiation, synchrotron-Cherenkov radiation

PACS: $41.60 .-m, 41.60 . A p, 41.60 . B q, 03.50 .-z, 03.50 . D e$

\section{Introduction}

In case of the charged particles moving in magnetic field, three kinds of radiation are possible in a medium [1-5]: synchrotron, Cherenkov, and synchrotron-Cherenkov. In papers [5-11] the authors studied the particularities of the synchrotron-Cherenkov radiation spectrum in a transparent medium with the relativistic longitudinal component of the velocity (the component parallel to the magnetic induction vector).

The aim of this paper is to investigate the spectral distribution of the radiation power for an electron moving in magnetic field using the improved Lorentz's self-interaction method [4,5]. Using the exact integral relationships for the spectral distribution of the radiation power of an electron moving along a spiral in a transparent isotropic medium, the fine structure of the electromagnetic radiation spectrum at the Cherenkov threshold and synchrotron-Cherenkov radiation spectrum was investigated by means of analytical and numerical methods. The action of the Doppler effect on the particularities of radiation spectrum of a single electron at its motion in a spiral in a transparent medium with non-relativistic longitudinal component of the velocity (i.e., the component parallel to the magnetic induction vector) is investigated.

\section{Time-averaged radiation power of charged particles}

The time-averaged radiation power $\bar{P}^{\text {rad }}$ of charged particles moving in a transparent isotropic medium is expressed in $[4,5]$ as

$$
\bar{P}^{\mathrm{rad}}=\lim _{T \rightarrow \infty} \frac{1}{2 T} \int_{-T}^{T} \mathrm{~d} t\left\{\int_{\tau}\left(\vec{j}(\vec{r}, t) \frac{1}{c} \frac{\partial \vec{A}^{\mathrm{Dir}}(\vec{r}, t)}{\partial t}-\rho(\vec{r}, t) \frac{\partial \varphi^{\mathrm{Dir}}(\vec{r}, t)}{\partial t}\right) \mathrm{d} \vec{r}\right\} .
$$

Here $\vec{j}(\vec{r}, t)$ is the current density and $\rho(\vec{r}, t)$ is the charge density. The integration is over the volume $\tau$. According to the hypothesis of Dirac [12-15], the scalar $\varphi^{\text {Dir }}(\vec{r}, t)$ and vector $\vec{A}^{\text {Dir }}(\vec{r}, t)$ potentials are defined as a half-difference of the retarded and advanced potentials.

*E-mail: aconst@ukr.net 
After substituting the scalar $\varphi^{\text {Dir }}(\vec{r}, t)$ and vector $\vec{A}^{\text {Dir }}(\vec{r}, t)$ potentials into $(1)$ we obtain the relationship for the average radiation power of charged particles moving in a transparent isotropic medium:

$$
\bar{P}^{\mathrm{rad}}=\int_{0}^{\infty} \mathrm{d} \omega W(\omega)
$$

where

$$
\begin{aligned}
W(\omega)= & \lim _{T \rightarrow \infty} \frac{1}{2 T} \int_{-T}^{T} \mathrm{~d} t W(t, \omega), \\
W(t, \omega)= & \frac{1}{\pi c^{2}} \int_{-\infty}^{\infty} \mathrm{d} \vec{r} \int_{-\infty}^{\infty} \mathrm{d} \overrightarrow{r^{\prime}} \int_{-\infty}^{\infty} \mathrm{d} t^{\prime} \omega \mu(\omega) \frac{\sin \left(\frac{n(\omega)}{c} \omega\left|\vec{r}-\vec{r}^{\prime}\right|\right)}{\left|\vec{r}-\overrightarrow{r^{\prime}}\right|} \\
& \times \cos \left\{\omega\left(t-t^{\prime}\right)\right\}\left\{\vec{j}(\vec{r}, t) \vec{j}\left(\overrightarrow{r^{\prime}}, t^{\prime}\right)-\frac{c^{2}}{n^{2}(\omega)} \rho(\vec{r}, t) \rho\left(\overrightarrow{r^{\prime}}, t^{\prime}\right)\right\} .
\end{aligned}
$$

Here $W(\omega)$ is a function of the average spectral distribution of radiation power, $W(t, \omega)$ is a function of the instantaneous spectral distribution of radiation power, $\mu(\omega)$ is the magnetic permeability, $n(\omega)$ is the refraction index, $\omega$ is the cyclic frequency, and $c$ is the velocity of light in vacuum.

\section{Radiation spectrum of an electron moving along a spiral with a low lon- gitudinal component of the velocity}

The motion law and the velocity of an electron moving in a spiral in a transparent medium are given by the expressions

$$
\vec{r}(t)=r_{0} \cos \left(\omega_{0} t\right) \vec{i}+r_{0} \sin \left(\omega_{0} t\right) \vec{j}+V_{\|} t \vec{k}, \quad \vec{V}(t)=\frac{\mathrm{d} \vec{r}(t)}{\mathrm{d} t} .
$$

Here $r_{0}=V_{\perp} \omega_{0}^{-1}, \omega_{0}=c e B^{\text {ext }} \tilde{E}^{-1}, \tilde{E}=c \sqrt{p^{2}+m_{0}^{2} c^{2}}$, the magnetic induction vector $\vec{B}^{\text {ext }} \| 0 Z$, $V_{\perp}$ and $V_{\|}$are the components of the velocity, $\vec{p}$ and $\tilde{E}$ are the momentum and energy of the electron, $e$ and $m_{0}$ are its charge and rest mass. We obtain the time-averaged radiation power of an electron after substituting (5) into (2) to (4). Then (see [4,5])

$$
\begin{aligned}
\bar{P}^{\mathrm{rad}} & =\int_{0}^{\infty} \mathrm{d} \omega W(\omega), \\
W(\omega) & =\frac{2 e^{2}}{\pi c^{2}} \int_{0}^{\infty} \mathrm{d} x \omega \mu(\omega) \frac{\sin \left(\frac{n(\omega)}{c} \omega \eta(x)\right)}{\eta(x)} \cos (\omega x)\left\{V_{\perp}^{2} \cos \left(\omega_{0} x\right)+V_{\|}^{2}-\frac{c^{2}}{n^{2}(\omega)}\right\},
\end{aligned}
$$

where $\eta(x)=\sqrt{V_{\|}^{2} x^{2}+4 \frac{V_{\perp}^{2}}{\omega_{0}^{2}} \sin ^{2}\left(\frac{\omega_{0}}{2} x\right)}$.

After some transformations from relationships (6) and (7) for the longitudinal component of the velocity $V_{\|}<c / n(\omega)$ the contributions of separate harmonics to the averaged radiation power of the electron can be expressed as

$$
\begin{aligned}
\bar{P}^{\mathrm{rad}}= & \frac{e^{2}}{c^{3}} \sum_{m=1}^{\infty} \int_{0}^{\infty} \mathrm{d} \omega \mu(\omega) n(\omega) \omega^{2} \int_{0}^{\pi} \sin \theta \mathrm{d} \theta \delta\left\{\omega\left(1-\frac{n(\omega)}{c} V_{\|} \cos \theta\right)-m \omega_{0}\right\} \\
& \times\left\{V_{\perp}^{2}\left[\frac{m^{2}}{q^{2}} J_{m}^{2}(q)+J_{m}^{\prime 2}(q)\right]+\left(V_{\|}^{2}-\frac{c^{2}}{n^{2}(\omega)}\right) J_{m}^{2}(q)\right\},
\end{aligned}
$$


where $q=V_{\perp} \frac{n(\omega)}{c} \frac{\omega}{\omega_{0}} \sin \theta, \quad J_{m}(q)$ and $J_{m}^{\prime}(q)$ are the Bessel function with an integer index and its derivative, respectively.

For the velocities $V_{\|}<c / n(\omega)$ each harmonics is a set of the frequencies, which are determined from the solution of the equation

$$
\omega\left(1-\frac{n(\omega)}{c} V_{\|} \cos \theta\right)-m \omega_{0}=0
$$

\section{Spectral distribution of radiation power of an electron moving along a spiral near the Cherenkov threshold}

Let us consider some partial case when $\epsilon=$ const and $\mu=1$, i.e. the low-frequency spectral range is under investigation. The spectral distribution of radiation power $W(\omega)$ in transparent isotropic medium at the velocity absolute value $V_{\text {med }}=c / n=0.2306 \cdot 10^{11} \mathrm{~cm} / \mathrm{s}$ at $B^{\text {ext }}=1 G s$, $\mu=1, \quad n=1.3$ is presented in figures 1 and 2 . These calculations were carried out by using the relationship (7).

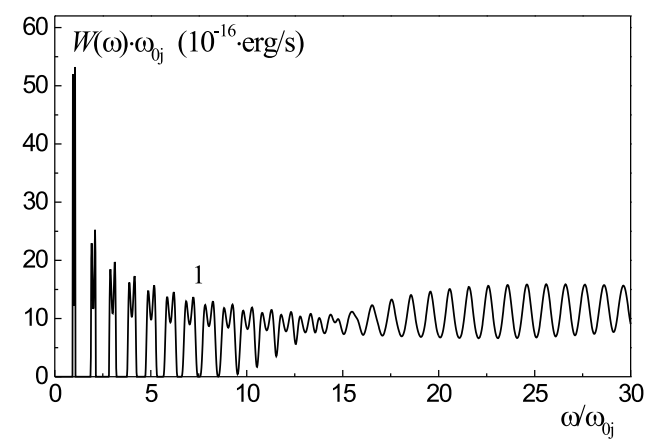

Figure 1. Spectral distribution of radiation power of an electron moving in a spiral in a medium at the velocity absolute value $V_{\text {med }}=$ $c / n=0.2306 \cdot 10^{11} \mathrm{~cm} / \mathrm{s}$ at low harmonics at $B^{\text {ext }}=1 G s, \mu=1, n=1.3, \quad V_{\perp \text { med }}=0.2301$. $10^{11} \mathrm{~cm} / \mathrm{s}, \quad V_{\| \operatorname{med}}=0.15 \cdot 10^{10} \mathrm{~cm} / \mathrm{s}, \quad r_{01}=$ $2048 \mathrm{~cm}, \omega_{01}=0.1124 \cdot 10^{8} \mathrm{rad} / \mathrm{s}, \quad c=0.2998$. $10^{11} \mathrm{~cm} / \mathrm{s}, \quad P_{\text {med } 1}^{\mathrm{int}}=\bar{P}_{1}^{\mathrm{rad}}=0.2629 \cdot 10^{-13} \mathrm{erg} / \mathrm{s}$.

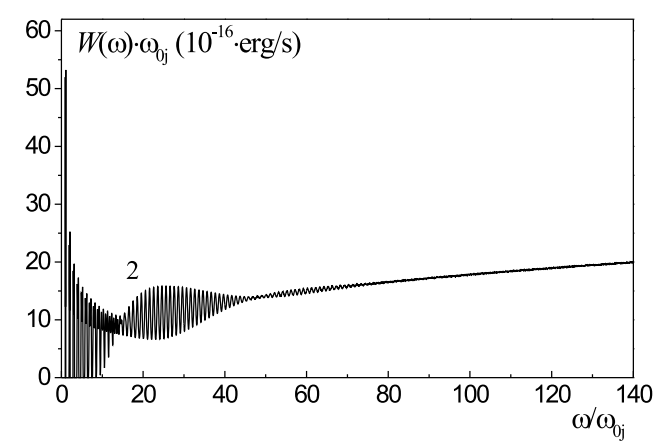

Figure 2. Spectral distribution of radiation power of an electron moving in a spiral in a medium at the velocity absolute value $V_{\text {med }}=$ $c / n=0.2306 \cdot 10^{11} \mathrm{~cm} / \mathrm{s}$ at high harmonics at $B^{\text {ext }}=1 G s, \mu=1, \quad n=1.3, \quad V_{\perp \text { med }}=$ $0.2301 \cdot 10^{11} \mathrm{~cm} / \mathrm{s}, V_{\| \text {med }}=0.15 \cdot 10^{10} \mathrm{~cm} / \mathrm{s}$, $r_{02}=2048 \mathrm{~cm}, \omega_{02}=0.1124 \cdot 10^{8} \mathrm{rad} / \mathrm{s}, \quad c=$ $0.2998 \cdot 10^{11} \mathrm{~cm} / \mathrm{s}, P_{\mathrm{med} 2}^{\text {int }}=0.2085 \cdot 10^{-12} \mathrm{erg} / \mathrm{s}$.

For the case $V_{\text {med }}=c / n=0.2306 \cdot 10^{11} \mathrm{~cm} / \mathrm{s}$ at the Cherenkov's threshold the overlapping between the harmonics was studied. As one can see in figure 1, the overlapping between the harmonic shifts to the higher harmonics with a decreasing longitudinal component of the velocity.

At higher harmonics the maxima in the spectral distribution of the radiation are caused mainly by the overlapping between the neighbouring $m^{\text {th }}$ and $(m+1)^{\text {th }}$ harmonics (see figures 1 and 2 ) as well as by some contributions of other harmonics.

The spectral distribution of the synchrotron-Cherenkov radiation power in transparent medium above the Cherenkov threshold (a velocity absolute value $V_{\text {med }}>c / n$ ) at $B^{\text {ext }}=1 G s, \mu=1$, $n=1.3$, is presented in figures 3 and 4 . The high-accuracy numerical calculations according to relationships (6) and (7) have shown that the synchrotron-Cherenkov radiation of the electron moving in a spiral in a medium $(\mu=1, n=1.3)$ is an unified process [3,5] and made it possible to obtain the magnitude of radiation power $P_{\operatorname{med} j}^{\text {int }}=\bar{P}_{j}^{\mathrm{rad}}$. 


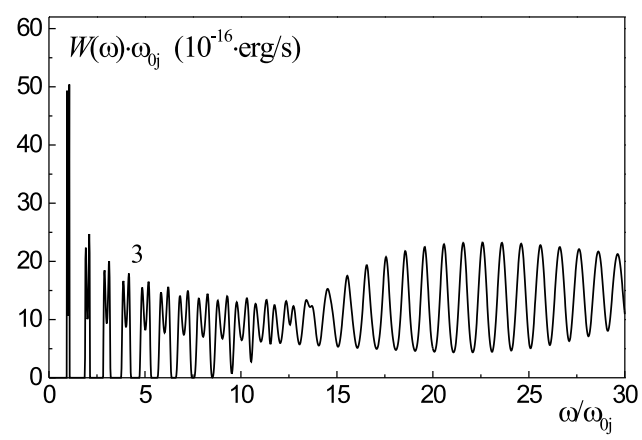

Figure 3. Spectral distribution of synchrotronCherenkov radiation power at the velocity absolute value $V_{\text {med }}>c / n$ at low harmonics at $B^{\text {ext }}=1 G s, \mu=1, \quad n=1.3, \quad V_{\perp \text { med }}=$ $0.24 \cdot 10^{11} \mathrm{~cm} / \mathrm{s}, \quad V_{\| \operatorname{med}}=0.15 \cdot 10^{10} \mathrm{~cm} / \mathrm{s}$, $r_{03}=2285 \mathrm{~cm}, \omega_{03}=0.1050 \cdot 10^{8} \mathrm{rad} / \mathrm{s}$, $P_{\text {med } 3}^{\text {int }}=0.3058 \cdot 10^{-13} \mathrm{erg} / \mathrm{s}$.

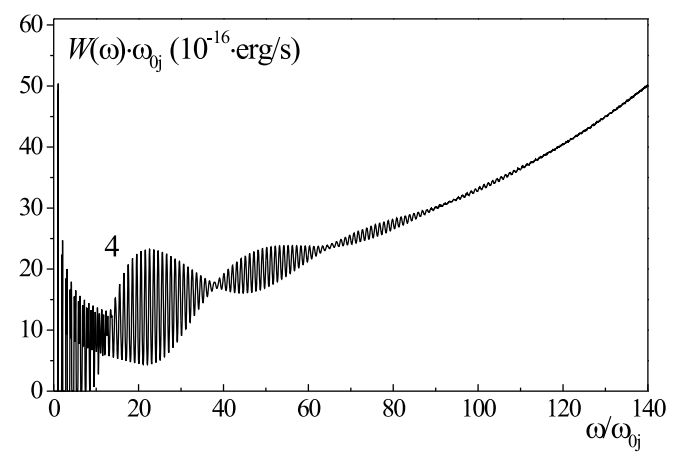

Figure 4. Spectral distribution of synchrotronCherenkov radiation power at the velocity absolute value $V_{\text {med }}>c / n$ at high harmonics at $B^{\text {ext }}=1 G s, \mu=1, \quad n=1.3, \quad V_{\perp \text { med }}=$ $0.24 \cdot 10^{11} \mathrm{~cm} / \mathrm{s}, \quad V_{\| \operatorname{med}}=0.15 \cdot 10^{10} \mathrm{~cm} / \mathrm{s}$, $r_{04}=2285 \mathrm{~cm}, \omega_{04}=0.1050 \cdot 10^{8} \mathrm{rad} / \mathrm{s}$, $P_{\text {med } 4}^{\text {int }}=0.3579 \cdot 10^{-12} \mathrm{erg} / \mathrm{s}$.

At higher harmonics, the maxima in the spectral distribution of the synchrotron-Cherenkov radiation are caused mainly by the overlapping between the $m^{\text {th }}$ and $(m+1)^{\text {th }}$ harmonics (see figures 3 and 4) as well as by some contributions of other harmonics.

As one can see in figures 1 to 4 all the calculated spectral dependencies of the radiation power spectral distribution are of a non-monotonous character near the Cherenkov threshold.

\section{Conclusions}

For a non-relativistic longitudinal component of the electron velocity, the overlapping between the harmonics begins at higher harmonics number with a decreasing longitudinal component of the velocity.

At higher harmonics, the maxima in the spectral distribution of the synchrotron-Cherenkov radiation are caused mainly by the overlapping between the $m^{\text {th }}$ and $(m+1)^{\text {th }}$ harmonics.

The spectral dependence of the radiation power spectral distribution is of a non-monotonous character near the Cherenkov threshold. 


\title{
References
}

1. Tsytovich V.N. Bulletin of Moskow State University, 1951, No. 11, 27 (in Russian).

2. Konstantinovich A.V., Nitsovich V.M. Izv. Vuzov. Fizika, 1973, No. 2, 59 (in Russian).

3. Schwinger J., Wu-Yang Tsai, Erber T. Ann. Phys., 1976, 96, 303.

4. Konstantinovich A.V., Melnychuk S.V., Rarenko I.M., Konstantinovich I.A., Zharkoy V.P. J. Physical Studies, 2000, 4, 48 (in Ukrainian).

5. Konstantinovich A.V., Melnychuk S.V., Konstantinovich I.A. Journal of Optoelectronics and Advanced Matterials, 2003, 5, 1423.

6. Konstantinovich A.V., Melnychuk S.V., Konstantinovich I.A. Romanian Journal of Physics, 2003, 48, No. 5-6, 717.

7. Konstantinovich A.V., Melnychuk S.V., Konstantinovich I.A. Proceedings of the Romanian Academy A., 2003, 4, No. 3, 175.

8. Konstantinovich A.V., Konstantinovich I.A. Romanian Journal of Optoelectronics, 2004, 124, No. 3, 13.

9. Konstantinovich A.V., Melnychuk S.V., Konstantinovich I.A. Romanian Journal of Physics, 2005, 50, No. 3-4, 347 .

10. Konstantinovich A.V., Konstantinovich I.A. Physics and Chemistry of Solid State, 2005, 6, No. 4, 535 (in Ukrainian).

11. Konstantinovich A.V., Melnychuk S.V., Konstantinovich I.A. Journal of Materials Science: Materials in Electronics, 2006, 17, No. 4, 315.

12. Dirac P.A.M. Proc. Roy. Soc. A, 1938, 167, 148.

13. Sokolov A.A. Bulletin of Moskow State University, 1947, No. 2, 33 (in Russian).

14. Schwinger J. Phys. Rev. 1949, 75, 1912.

15. Konstantinovich A.V., Melnychuk S.V., Konstantinovich I.A. Bulletin of Chernivtsi National University, Physics and Electronics, 2001, No. 102, 5 (in Ukrainian).

\section{Спектр випромінювання електрона, що рухається вздовж гвинтової лінії у середовищі}

\author{
А.В.Константинович, І.А.Константинович \\ Чернівецький національний університет ім. Юрія Федьковича, \\ вул. Коцюбинського 2, 58012, Чернівці
}

Отримано 4 вересня 2006 р., в остаточному вигляді - 27 грудня 2006 р.

Досліджено вплив ефекту Доплера на особливості спектрального розподілу потужності випромінювання електрона, що рухається вздовж гвинтової лінії у середовищі, поблизу черенковського бар'єру. Отримана і досліджена тонка структура електромагнітного спектра на черенковському бар'єрі та спектра синхротронно-черенковського випромінювання електрона, що рухається вздовж гвинтової лінії у прозорому середовищі, з нерелятивістською поздовжньою компонентою швидкості (компонентою, що паралельна вектору магнітної індукції).

Ключові слова: синхротронне випромінювання, синхротронно-черенковське випромінювання

PACS: 41.60.-m, 41.60.Ap, 41.60.Bq, 03.50.-z, 03.50.De 
